\title{
LA CONDICIÓN FANÁTICA: PARADOJAS DE VIDA Y MUERTE ${ }^{1}$
}

\author{
Teresa Sánchez Sánchez ${ }^{2}{ }^{3}$ \\ Facultad de Psicología. UPSA, Salamanca
}

\begin{abstract}
El fanatismo germina en todo tipo de ambientes culturales, religiosos, deportivos y mediáticos. Recorremos en este artículo los factores psicológicos presentes en las actitudes totalitarias. El intolerante deviene intolerable para la sociedad que sordamente lo ha alimentado. Puro conglomerado de paradojas contrapuestas, de vida y muerte, se albergan en un útero ideológico insatisfecho y sin respuestas. Algunas de estas antinomias son: a mayor invisibilidad, mayor morbilidad; la idiotez moral correlaciona con la contundencia razonadora de los argumentos justificativos; su despersonalización les convierte en instrumento, pero no asumen la responsabilidad o culpa de su acción; se viven como víctimas pese a actuar como verdugos; su muerte o inmolación son actos nihilistas de exaltación de la vida distorsionada en su valor; el fanático se siente más plenamente realizado cuanto más alienado está.
\end{abstract}

Palabras clave: Dogmatismo, Fanatismo, Paradojas, Muerte y Vida, Alienación.

Fanaticism breaks out in any culture, religion, sport or media environment. This paper reviews psychosocial factors involved in fanatic attitudes. Intolerant people become intolerable for a society that surreptitiously boosts intolerance. A sheer conglomerate of existential, relational and emotional paradoxes, sheltered in an ideological unhappy womb, without any reply. Among these antinomies are the following: the higher the invisibility, the higher the morbidity.; the moral idiocy relates to severity of explaining reasons; their depersonalization turns them into instruments, but not into responsible and guilty agents; they live like victims although they behave as executioners; their death or sacrifice is a nihilistic event extolling their value-distorted life; the more they are alienated, the more they feel realized.

Key Words: Dogmatism, Fanaticism, Paradoxes, Death and Life, Alienation.

English Title: THE FANATIC CONDITION: PARADOXES OF LIFE AND DEATH

\section{Cita bibliográfica / Reference citation:}

Sánchez Sánchez, T. (2019). La condición fanática. Paradojas de vida y muerte. Clínica e Investigación Relacional, 13 (2): 365-388. [ISSN 1988-2939] [Recuperado de www.ceir.info] DOI: 10.21110/19882939.2019.130204

\footnotetext{
${ }^{1}$ El presente texto es la versión revisada de la conferencia pronunciada en Ágora Relacional (Madrid) el 5 de abril de 2018.

2 Teresa Sánchez Sánchez. Doctora en Psicología. Profesora titular de Universidad. Imparte "Intervención Psicodinámica" (y otras 5 asignaturas más) en la Facultad de Psicología de la Universidad Pontificia de Salamanca. Profesora del Master de Psicología General Sanitaria (Módulos: Deontología, Duelo patológico, Suicidio). Profesora y colaboradora de otros grupos de Psicoterapia: Centro Self (adscrito a IPR). Profesora del Máster y del Curso de Especialista en Psicoterapia Psicoanalítica codirigido y auspiciado por la UPSA. Psicoterapeuta Psicoanalítica. Asociación Psicoanalítica "Oskar Pfister". Terapeuta en Salamanca durante 30 años (Centro "Athanor"). Ganadora del $2^{\circ}$ Premio FEAP en 2012 con el trabajo "Del traumatismo al trauma. Desorganización y resiliencia en la elaboración postraumática". Autora de varios libros: "La mujer sin identidad" (Ed. Amarú), "Psicoanálisis y Psicología: Convergencia y confrontación" (Ed. Biblioteca Nueva), "Psicoanálisis: Evaluación epistemológica y modelos de validación empírica" (Ed. Universidad de Salamanca), "¿Qué es la Psicosomática? Del silencio de las emociones a la enfermedad" (Ed. Biblioteca Nueva". "Maltrato de género, infantil y de ancianos" (Ed. Universidad Pontificia de Salamanca). Autora de más de 100 artículos publicados en revistas especializadas. Participé en el III Congreso FEAP celebrado en noviembre del 2017 en Madrid. Conferenciante habitual invitada a diversos foros, universidades y asociaciones. Colaboro con el Instituto Europeo de Psicoterapia y con la Sociedad Española de Medicina Psicosomática, entre otras agrupaciones profesionales.
}

3 ORCID: 0000-0002-2711-7423

CelR Vol. 13 (2) - Octubre 2019 ISSN 1988-2939 - www.ceir.info

(c) Derechos reservados/Copyright de Clínica e investigación Relacional y los autores. Prohibida la reproducción total o parcial sin autorización expresa. Este material es para uso científico y profesional exclusivamente y puede contener información clínica sensible. Los editores no se responsabilizan de los contenidos de los autores. Dirigir las consultas sobre derechos y autorizaciones a ceir@psicoterapiarelacional.es 
"Las cosas que más excitan a la gente poco reflexiva son las que no existen" (Jesús Mosterín).

"Las mentes grandes discuten ideas; las medianas, cosas; las pequeñas, personas" (Proverbio chino).

\section{o. Sobre el término.}

Deriva de fanum: templo, siendo el fanático el defensor y guardián del templo, alguien bendito, consagrado y puro. Los fanatici tenían encomendado el proselitismo mediante el efecto seductor y contagioso de sus danzas rituales paroxísticas y ejercían un efecto extático en el pueblo. Las apoteosis fanáticas poseen, de hecho, un componente ceremonial, unas liturgias de transformación a estados ontológicamente superiores. El ardor o desmesura en las manifestaciones no connota de antemano ni positiva ni negativamente el valor de la postura: un fanático del arte será un decidido protector del patrimonio artístico, en tanto que un fanático integrista destruirá todo el patrimonio que no concuerde con sus a priori ideológicos. La RAE lo define como el que "defiende con tenacidad desmedida y apasionamiento, creencias $u$ opiniones, sobre todo religiosas o políticas. Preocupado o entusiasmado ciegamente por una cosa". Si lo preocupado apunta a un componente obsesivo, lo entusiasta apunta a un fervor maníaco y lo ciegamente a un núcleo paranoico. Sin saberlo, probablemente, la Academia de la Lengua ha dado con el quid del triángulo psicopatológico común en los fanáticos.

El fanatismo es una actitud cognitiva, emocional y conductual, que nace, se retroalimenta y proyecta sobre el entorno cercano o remoto anegando y eclipsando el juicio, una "gangrena mental de difícil cura", al decir de Voltaire, que se pertrecha de argumentaciones racionales para sostener la hostilidad e intransigencia de sus sesgos y que desprende una praxis destructiva hacia todo y todos los que representan o encarnan lo otro, lo distinto. Borra el pluralismo, prohíbe la discrepancia, impone el pensamiento único y la censura de lo extraño. Utrilla (2018) connota el fanatismo con parecidos trazos a los que aquí desarrollaremos: fe irracional, maniqueísmo, odio al extraño y afán despótico de proliferar e imponer su credo. Pero procede, sin embargo, introducir algunas aclaraciones: el fanático no es solo un supersticioso: éste carece de su combatividad y mesianismo; no es solo dogmático: éste no ha de ser necesariamente agresivo, aunque sí sea rígido; no es solo un estulto, ya que la estupidez no conduce necesariamente a la propaganda; no es solo un maniqueo, ya que los niños y las mentalidades más simples también lo son. Es preciso que se conjuguen todos esos rasgos en un cóctel aliñado por vivencias de fracaso y frustración que no encuentran salida evolutiva, sino involutivamente. Pallarés lo describió con los siguientes trazos: "irracional, desmesurado, violento, engreído, inflexible, autoritario, exaltado... con algo de misticismo y de profetismo..." (1996, p. 35). 


\section{Procesos psíquicos presentes en el Fanatismo.}

En su muy reciente obra Líderes y Liderazgos, Utrilla (2018) especifica algunos procesos psíquicos presentes en los procesos de fanatización: sumisión, simbiosis, confusión y robotización, todo ello sostenido por una idealización acrítica de un líder grandioso o de una idea grandiosa y absolutizada. En el desarrollo dinámico que aquí se propone, los componentes que actúan como base son los siguientes:

a) Intensa adhesión a una idea universalizada, convertida mágicamente en 'la verdad'absoluta. En un pequeño artículo de 1910 titulado "El fanático", Chesterton recalcó la "incapacidad de una mente para imaginarse otra mente" y explicó una fuente del fanatismo que hoy se apoyaría en la Teoría de la Mente del cognitivismo y en la Teoría de la Mentalización del Psicoanálisis: "Todos los hombres deben ver un cosmos como el verdadero; pero el fanático no puede ver ningún otro cosmos, ni siquiera como una hipótesis" (p. 142). Habría, pues, un fracaso en la especularización mental del otro, consecuencia de no haber sido reflejado correctamente por la mente de nadie. Coincide con el aforismo de $\mathrm{Oz}$ (2018, p. 31) en su libro Queridos fanáticos: "el fanático no sabe sumar más de uno".

b) Actitud de fe firme que deja en penumbra el funcionamiento racional, haciendo abdicar a la razón crítica. Esto se concreta en la obcecación y sumisión sin fisuras a un dogma. Margaret Atwood, autora de culto tras la reedición de su distopía "El cuento de la criada", lo explica con claridad meridiana: "Cuando la ideología se convierte en religión, cualquiera que no imita las actitudes extremistas es visto como un apóstata, un hereje o un traidor... las personas somos moralmente ambiguas. El objetivo de la ideología (fanatizada) es eliminar la ambigüedad" (1985, p. 324). Sin ella pretenderlo, está apuntando a una posición esquizoparanoide, donde no se ha accedido a la integración o la síntesis de la complejidad y la posición depresiva de la relación con un objetototal.

c) Rechazo, ataque, menosprecio de todo lo que se vive como diferente. La minusvaloración o degradación del otro o de lo otro es la piedra angular de la intransigencia, y nos habla de una fuerte patología narcisista (Armengol, 1999), que cuando es compartida por un grupo, raza o un pueblo frente a otros degenera en xenofobia, racismo, genocidio, etc. En el fanático, el miedo o la prevención ante lo novedoso o diferente se transforma en recelo persecutorio, de forma que lo nuevo es extraño, lo extraño es potencialmente desestabilizador o peligroso, y por consiguiente malo. Como defensa contra la ansiedad a lo desconocido o distinto, se establece el mecanismo esquizoparanoide que sitúa lo bueno en el mí o el 'nosotros' conocido o cercano y todo lo malo y nocivo en el otro o 'ellos'. El sentimiento de amenaza indica que hay una latente arrogancia que niega o degrada en los diferentes su condición humana (Arendt, 1993), la rebaja 
hasta un nivel subhumano o de rebaño: "Para el xenófobo el grupo contrario carece de rostro, lo que lo convierte en algo semejante a un rebaño o a un bosque, con la diferencia de que a sus ojos el rebaño se convierte en una manada de lobos" (Lucena, 1994, p. 152). Burris y Rempel (2008) emplean el concepto "devaluación" del prójimo, mientras Baca (2014) estudia el proceso de "construcción del enemigo". A su juicio, en la violencia fanática, sobre todo de tintes religiosos y políticos, se actúa sobre individuos próximos, encarnaciones del sistema, pero luego se generaliza a objetivos menos específicos. La inercia de la violencia concluye cuando se culpa a la víctima de su propia destrucción (Baca, 2003).

Cuando S. Drakulic acudió como observadora a los Juicios del Tribunal de La Haya contra algunos criminales de guerra de la ex Yugoslavia, ahondó en la experiencia que se va fraguando paso a paso, imperceptiblemente, hasta que el chico de buen carácter a veces termina lavando sus manos manchadas de sangre:

Para empezar, es importante identificar el objeto y ofrecer razones convincentes para el odio. Las razones no tienen que ser racionales ni siquiera necesariamente ciertas. Lo más importante es que sean convincentes para que la gente las acepte. Tales explicaciones suelen basarse en mitos (...) y en prejuicios (los serbios son primitivos, los croatas son nazis, los musulmanes son estúpidos...). Y ayuda si esos mitos y prejuicios están arraigados en la realidad, ya sea en la historia de guerras anteriores o en diferencias culturales y religiosas.

(...)La tarea de la propaganda es moldear esa diferencia para generar la impresión de que ese otro supone una amenaza y reforzar la urgencia de la homogenización. Más importante es el método de introducir el odio: es más eficaz si la gente se acostumbra a él poco a poco, paso a paso, hasta que lo absorbe en su vida cotidiana.

A la luz de las 'pruebas' que demuestran esas diferencias (a menudo descripciones e abusos y atropellos -reales o ficticios- en los medios de comunicación), esos 'otros' son despojados de sus rasgos individuales. Ya no son conocidos como profesionales con sus nombres particulares, sus costumbres, aspecto y carácter, sino que se ven restringidos a su condición de miembros del grupo enemigo. Cuando una persona se ve reducida de ese modo a una abstracción, uno es libre de odiarla porque el obstáculo moral ya ha sido abolido. Si se ha 'probado' que nuestros enemigos ya no son seres humanos, ya no estamos obligados a tratarlos como tales. Y no importa que, al hacerlo así, nosotros también nos reduzcamos a una categoría abstracta, que ya no seamos individuos porque, a los ojos del enemigo, somos también los otros (Drakulic, 2008, 201-202).

d) Subversión o perversión del uso del instrumento racional que se utiliza justificativamente al servicio de la argumentación trascendental de la idea o creencia sobrevalorada, pero se hace opaca y refractaria a cualquier idea contrapuesta o capaz de introducir dudas o réplicas a la misma. La libertad de pensar queda fuertemente mermada. Una de las primeras y principales armas en el proceso de adoctrinamiento y fanatización es la perversión del lenguaje. Un ejemplo 
claro es el uso de términos eufemísticos que edulcoran y embellecen la verdad. El Anschluss austríaco maquilló como anexión voluntaria lo que había sido una invasión fundada en la traición de Schuschnigg ante Goring. (Vuillard, 2018).

Es fácil para los líderes políticos utilizar imágenes como las que yo recuerdo, usar la memoria emocional de la gente y construir el odio sobre ella (...) Los líderes políticos pueden apelar a esas imágenes, mezclarlas con mitología popular y agitar las emociones repitiéndolas incansablemente en la televisión (...) Bajo la presión de las emociones, cae fácilmente la fina capa de racionalidad. (Drakulic, 2008, p. 31).

e) Emocionalidad primaria e irracional, individual o grupal, como sustrato de la idea fanática; dicha emocionalidad opera como fuente energética bruta, sin canalización, diques morales o legales que actúen como freno o cauce, por lo que inunda los demás aspectos o facetas de la personalidad convirtiéndose en torrentera desbordante que anegará cualesquiera otros intereses o desarrollos posibles. Una de las emociones más cultivadas es el desprecio al diferente y el amor incondicional a la idea y a sus representantes con los que se compone un núcleo simbiótico y sin orillas o disidencias internas. El desprecio a los otros ejerce un efecto aglutinador que infantiliza el pensamiento, evitando todo elemento crítico venido de fuera, impermeabilizándose frente a ello. La necesidad populista de que la historia sea falsificada para que se acomode a los deseos y mitos privados, o que dé respuesta a sus frustraciones y fracasos, es aprovechada demagógicamente para la falsificación de la historia. Así lo desarrolla y argumenta Gómez de Liaño (2019) en su obra reciente:

El propósito de la educación totalitaria nunca ha sido infundir convicciones sino destruir la capacidad para formar alguna. En este limbo desnortado donde hinca sus raíces (cualquier movimiento fanático) impone sus 'verdades orgánicas' surgidas de la manipulación y cocinadas a gusto del manipulador a partir de presuntos datos históricos sin contrastar y de mitologías baratas (2019, p. 247)

f) Gran afán proselitista, inducido por la convicción de poseer la verdad, por la necesidad de diluir responsabilidades en el grupo heteróclito, por el deseo de reaseguramiento en la propia verdad a través del eco reverberante que se aprecia en los otros conversos. A este fin concurren los mensajes seductores, las campañas, profecías intimidatorias, mítines, comunicados, que se descargan sobre los receptivos correligionarios con la aureola de una verdad revelada y casi ultraterrena. Tal como señalaba Primo Levi "la propaganda sustituye a la información" (Levi, 1976).

La acción fanática disminuiría su poder si no obtuviera publicidad. La reivindicación de una acción claramente efractora es una estrategia proselitista que pretende incendiar el ánimo de los simpatizantes tibios, exacerbar su odio larvado, agitar conciencias estimulando el resentimiento latente. Y cuando el odio se expresa privadamente, sólo manifiesta una herida narcisista, pero 
cuando se expresa ante testigos, se configura como una fórmula para la adhesión de nuevos militantes. Por consiguiente, cuanto más vistosa y efectista sea una acción totalitaria, tanto más eficaz será desde el punto de vista del reclutamiento de candidatos, dado que enardece sádicamente la violencia primaria de los espectadores afines. No concuerda con este punto de vista, sin embargo, Amos Oz, quien piensa: "que a la mayoría de los fanáticos no les mueve el sadismo, sino grandes ideas sublimes, anhelos de redención y justicia social y para alcanzarlos deben librarse de los malvados" (2018, p. 48).

El martirio (conduzca éste a la muerte o solo al sacrificio de algún bien personal) es esencial en la épica heroica de un fanático. A la par que le brinda un relato, una gesta afirmativa, le proporciona una "desnudez catastrófica" (Vilas, 2018) que le asegura la admiración de los menos valientes. Su carne sacrificada constituye, en un cierto modo paradojal, la apoteosis de la afirmación de la vida y de su inanidad, pues solo triunfa la idea, a la vez que perece la persona, la insignificante carne. Sabia conclusión, la de Oz:

A veces, el sacrificio de uno mismo es un arma fanática, precisa y afilada, que se utiliza para ejercer una destructiva manipulación sentimental" (Oz, 2018, p. 44).

Hay un tufo de elación maníaca en la expansividad de la exultante destrucción, en las bravatas, en las acciones multitudinarias de las turbas, en las proclamas ante las masas. Una unción megalómana que parece proclamar: "el mundo y la verdad nos pertenecen, que todos lo sepan". La apoteosis destructiva que nos asombró en los atentados de Sri Lanka del 21 de abril, al inmolarse casi una decena de terroristas causando varios centenares de muertos y heridos, expresa la grandiosidad del horror. El perfil de los perpetradores es diferente al esperado: jóvenes acomodados y con alto nivel educativo.

g) Impunidad del anonimato y ebriedad de poder: Observar a otras personas haciendo lo mismo, normalizando lo extravagante y extraordinario, induce una percepción de pseudonormalidad, una normopatía. Conocemos los procesos de dilución de la responsabilidad en el grupo y el sentimiento de impunidad que otorga la pertenencia a la masa. Y si, además, de sentirse a salvo se produce la metamorfosis de una identidad inane en otra poderosa, se habrá conseguido eludir la impotencia y reforzar la recompensa. El poder es una droga poderosa. Nuevamente, en reflexión de la periodista croata:

Te sientas en un tribunal y observas a un acusado día tras día; al principio, te preguntas... Pronto sientes que los conoces íntimamente. Observas sus rostros, feos o agradables, sus pequeños hábitos de bostezar, tomar notas, rascarse la cabeza, limpiarse las uñas, y tienes que preguntarte: ¿y si esto es un hombre? Cuanto más los conoces, más tienes que preguntarte si esos crímenes los habrán cometido todos esos camareros y taxistas, maestros y campesinos que se sientan frente a ti. Y cuanto más comprendes que los criminales de guerra podrían ser personas normales, más miedo sientes. Por supuesto, esto se debe a que 
las consecuencias son mucho más graves que si se tratara de monstruos. Si la gente normal comete crímenes de guerra, eso significa que cualquiera de nosotros podría cometerlos. Entonces entiendes por qué es tan fácil y cómodo aceptar que los criminales de guerra son monstruos, en lugar de estar de acuerdo con Ervin Staub en que "el mal que surge de una mentalidad ordinaria y es cometido por gente ordinaria es la norma, no la excepción. (Drakulic, 2008, p. 199).

El origen psicosocial del fanatismo apunta a unos focos sépticos de carácter ideológico y social, que prenderán con más o menos virulencia según la estructura de personalidad que se presente: madura/inmadura, patológica/normal; integrada/defensiva; realizada/ coartada, etc. A tenor de estas diferencias, el sujeto puede oponer una resistencia a las ideas publicitadas o presentar una permeabilidad sumamente captativa a las seducciones ideológicas. Por consiguiente, la personalidad actuará análogamente al sistema inmune. Si es una personalidad fuerte y bien formada, adecuadamente madura y suficientemente estable, se mantendrá firme y evacuará los mensajes doctrinarios recibidos mediante el normal funcionamiento de su sistema crítico, personalizado y transigente con la pluralidad. Si, por el contrario, es una personalidad inestable e insegura, con miedo a la libertad, al error personal, a la responsabilidad y a la incertidumbre, se aferrará ávidamente a cualquier propuesta doctrinaria que le tranquilice. Confundirá la seducción con la convicción, tomará por verdaderos los silbos de sirena, y será manipulable como una pobre cosa sin voluntad, robotizada.

En el análisis de la personalidad de Calvino y su oponente Castellio, que ocupó a S. Zweig (1936) y también a Roca Barea (2018, p.115), se expresa esta materialización nihilista del odio que encarnó Calvino y que él expresaba diciendo: "se quema a un hombre y se acaba con un enemigo". Calvino incitó a sus turbas adeptas a saquear e incendiar. Con ello unió a los titubeantes. Solo estando juntos se sentían impunes. Como individuos aislados experimentarían algún grado de culpa por sus acciones, pero como masa fervorosa podían dejar brotar toda la violencia disociada, reforzada y enaltecida tanto por la grey sin remordimientos, como por el "padre loco" encarnado en la autoridad de Calvino. De este modo, no solo eran inmunes a cualquier condena moral, sino que complacían al líder idealizado.

Javaloy (1983), en su tesis doctoral sobre Fanatismo, denomina a esta posición "sometimiento temeroso". Pero es posible que nos equivoquemos.

\section{Paradojas existenciales y emocionales presentes en la posición fanática.}

Algunas de las paradojas existenciales del fanatismo que considero especialmente significativas son las siguientes: 
a) Los núcleos fanáticos dan paz interior y preparan para el combate exterior: No existen personas absolutamente fanáticas o personas completamente carentes de fanatismo. El fanatismo, es un ingrediente o parte psicótica de la personalidad que está frecuentemente desarrollada en cada uno e implantada en su vida cotidiana, como ha sabido ver Mercedes Puchol (2016). Cualquiera de nosotros tiene núcleos fanáticos en su personalidad, los elementos beta de los que hablaba Bion (1975), y que contienen lo destructivo, maligno, inasumido e inintegrable de nuestra identidad. Consideramos fanático a alguien no porque otro no lo sea, sino porque el predominio de su componente destructivo disociado es mayor que en el de quien consideramos tolerante. Por tanto, no existe una demarcación cualitativa entre el totalitario y el no totalitario, como no existe entre el loco y el cuerdo, o entre el perverso y el normal, sino tan sólo un grado mayor o menor de conocimiento y control consciente de los núcleos fanáticos o una disociación o defusión de los mismos, que persistirían de forma autista y segregada de la personalidad. Los documentales sobre los episodios trágicos protagonizados por los davidianos en Waco y por los seguidores de Jim Jones y el Templo del Sol en la Guyana ilustran claramente esta paradoja. Los apacibles paraísos de serenidad devinieron los escenarios de suicidios colectivos, voluntarios o inducidos, que han dejado huella en la historia del siglo XX.

Partir de esto, a pesar de resultar tan revulsivo y difícil de admitir, es el primer paso para acceder a una madurez más tolerante. No hacerlo supondrá vivir las propias intransigencias como perfectamente legítimas e indignarse por los fanatismos ajenos por juzgarlos incomprensibles. Cuanto más irracionales e ignaros sean los núcleos absolutistas, con mayor ímpetu deberán ser evacuados, drenados, expulsados de nosotros. Lo que sucede en el fanático es que sus núcleos intransigentes no son rechazados por la vía de la crítica racional o moral, sino simplemente escindidos, apartados del yo y proyectados sobre otro que, así, deviene enemigo. Casi ningún intransigente reconoce serlo. Ve la intolerancia en el adversario y la postura propia se interpreta como razonable, necesaria y congruente respuesta a la hostilidad del otro. Estos mecanismos defensivos concatenados (escisión, disociación, renegación, proyección) permiten mantener una apariencia de dulzura, afabilidad y cordialidad que chocan con los actos impositivos y destructivos que ejecutan. La serenidad y la tranquilidad de conciencia y conducta al efectuar la acción bárbara dan la clave de esa escalofriante contradicción propia de los cuadros de psicosis: frialdad emocional interna y virulencia y agresividad conductual. El oxímoron que Fromm utilizó para reflejar esto es el de "fuego frío". Se conjuga la serenidad pacífica y la potencialidad explosiva que aguarda su oportunidad.

Podríamos asegurar que el principal aliado del fanatismo es la falta de lucidez y su principal remedio el pensamiento crítico. Krystal (1978) hipotetiza un proceso de "rendición letal" del yo crítico, que es previo a la muerte psíquica, y que abre la puerta al suicidio, el delirio o la somatización mortífera. Cómo no pensar que éste sea el humus ideal para la germinación de 
semillas fanáticas en todos aquellos que padecen hambre de ideales, de causas, de mitos o de legados que se transforman en compromisos de futuro:

La pendiente resbaladiza que conduce de las creencias a la barbarie: afirmación cada vez mayor de las convicciones propias, que se van impregnando de afectividad y haciéndose con ello refractarias a cualquier crítica racional; identificación de ese sistema de creencias emocionales con la identidad del grupo al que se pertenece de forma absoluta; designación de grupos próximos y competidores como enemigos peligrosos; decisión de exterminar al enemigo antes de que él pueda realizar su secreta intención de eliminarnos a nosotros... No hay terrorista que no esté convencido de que actúa en defensa propia. (Lázaro, 2013, p. 23).

b) A mayor invisibilidad y oscurantismo, mayor morbilidad y violencia: No olvidemos que, aunque suela adornarse con una semiología identificativa y ostentosa (cruces gamadas, cabezas rapadas o túnicas blancas en el Ku-klux-klan, por ejemplo), a menudo el fanatismo es silente y taimado, anida en la mente de cualquier persona con apariencia normal. A este propósito, y con lógica aplastante, afirma Muñoz Molina (2001) en su prodigiosa novela Sefarad, sobre la intolerancia cruel del siglo XX, lo siguiente: "si un miembro de la Gestapo tiene una cara normal, entonces cualquier cara normal puede ser la de alguien de la Gestapo".

El fanático puede estar camuflado o durmiente en el hábitat enemigo, puede poseer una habilidad camaleónica para pasar desapercibido, mostrar una excelente adaptación periférica a las costumbres de su 'adversario', pero mantener latente e intacto su odio y su resolución de dañarle en cuanto reciba la orden. Suele ser un perfecto infiltrado o tapado en el entorno sobre el que trama verter su odio. Dormida en su interior persiste la determinación de violentar a su enemigo, que deja de ser una persona real para ser un objetivo bélico. Kepel (2001), al reflexionar sobre los 19 pilotos suicidas que actuaron en Manhattan, constata este hecho, señalando: "La paradoja más inquietante reside en la capacidad de disimulo de los camicaces, que mantuvieron intactas sus convicciones extremas después de haber estado expuestos al funcionamiento de la sociedad occidental, incluso en sus aspectos más íntimos". El fanático enmascara su discurso bajo mantos culturales, racionalizadores, esteticistas o biologicistas, que le dan una pátina de socialmente correcto, fácil de creer y de defender. Los fanatismos no se presentan como tales, suelen estar bien pertrechados de teorías históricas, filosóficas, biológicas o de cualquier otra especie que dan una cobertura indiscutible a su postura, actitudes y creencias (Bleichmar, 2005).

Una paradoja sobresaliente es que el odio fanático permanece enquistado, incluso parece inexistente, dado el alto nivel de disimulada connivencia con el enemigo que puede alcanzar el sujeto totalitario, no se nota, pasa desapercibido, aguarda impasible la hora, el día señalado, la misión específica, para destaparse y aflorar. Si el odio se drenara en pequeñas -aunque crónicasmanifestaciones, se podrían adoptar medidas contra él, al tiempo que se desactivaría potencialmente su capacidad destructiva. En cambio, alimentado sordamente, aletargado en la 
conciencia, se mantiene tan vivo y feroz como el magma hirviente bajo una montaña helada en la superficie. Apunta García Gual en este sentido: "quien odia de verdad está dispuesto a morir con tal de satisfacer su venganza, y en esa decisión destructiva la ira profunda centellea bajo el odio" (García Gual, 2002, p. 171).

Cuanto más siniestro y desastroso es el daño causado cuando la idea pasa al acto, tanto menos perverso es, más sobrio y natural semeja su ejecutante, más banal parece la hazaña que va a acometerse. Los periodistas y analistas comentan sorprendidos y la serenidad con que Mohamed Atta y sus cómplices se encaminaban al avión que utilizarían para morir y para matar, como quien va a comprar pan. No hay una expresión desencajada, no se aprecia la iluminación en su rostro, ni el miedo o la angustia descomponen su marcha. La última noche de los pilotos suicidas cenaron comida rápida americana, se divirtieron al estilo americano. Previamente, habían obtenido buenas notas en sus estudios durante años, eran disciplinados aprendices de una cultura de la que abominaban, ni siquiera hicieron gala de un ardor especial en sus cultos o expresiones de fe. Su disfraz era bueno: podían ser turistas, viajantes de comercio, dueños de restaurantes o cualquier otra cosa. "Utilizaban desde hacía años las caretas de los adaptados" (VV.AA., 2002). Empero, algunos de ellos vivían demasiado intensamente la cultura americana que presuntamente odiaban como para que fuera un mero disimulo.

Esto es lo que causa asombro: que quienes han pasado a representar una de las gestas más aciagas de la historia de la humanidad y quienes fueron connotados como modernas encarnaciones de Satán, lograron pasar enteramente inadvertidos, no llevaban estampada en su frente ninguna de las iconografías habituales del mal. Su frío temple indica aburrimiento e indiferencia, no revelaba que iban a matar, tan solo iban a llevar a cabo un trabajo para el que se habían preparado técnicamente durante años, el trabajo de la venganza, venganza de un agravio previo en el que todos los ciudadanos occidentales, según ellos, habían cooperado pasivamente, por la simple razón de pertenecer a una civilización que habían declarado e imaginado enemiga del Islam.

El odio es tanto más peligroso, cuanto más frío sea o más desdén finja. Para alcanzar la eficacia vengadora deseada, fin último del odio enranciado, no conviene que el rencor explote en efusiones incendiarias. Es preciso que repose, que muestre continuidad y durabilidad, que no se mitigue por un vuelco veleidoso de sentimientos o por un cambio de actitud respecto al enemigo. Para aumentar su efectividad ha de obedecer a un plan, integrarse en un proyecto, seleccionar estrategias y medios, perfeccionar la preparación del héroe ejecutante. De otra forma la efusión fanática correría el riesgo de quedar en una traca de feria, en una nueva humillación ante el enemigo, que aumentaría la grandeza de éste al tiempo que dejaría en ridículo al vengador. Es preciso, por ello, que el fanático combine el furor del odio interno y soterrado y la flema 
externa del estratega. El odio fanático de esta especie es propio de lo que la psiquiatría tradicional designaba como locuras razonantes.

Ornstein (2009) aplica el concepto 'rabia narcisista', que da pábulo a manifestaciones con apariencia masoquista, sádica o paranoide. Surge, según ella, de un ser fragmentado o amenazado de fragmentación. Si el self se cohesiona, la rabia se transforma en duelo y tal vez en una irritación fugaz sin consecuencias. La rabia narcisista confiere a quien la experimenta un sentimiento de omnipotencia destructiva, y probablemente alimenta un narcisismo primario incapaz de evolucionar hacia el duelo (Martín Solar, 2018) que le daría acceso a la relación con los otros, a la inclusión adulta de los otros, y por supuesto al perdón.

c) El fanático es un idiota moral razonante pero poco razonable: Bilbeny (1993) los denomina "idiotas morales" pobres almas muertas, carentes de función empática, carentes de función reflexiva (incompetentes, por supuesto, para verse a sí mismos como en realidad son, en vez de cómo exaltadamente creen que son), y deficientes de la función de pensamiento. Esta insanía moral o banalización del mal de la que participa el fanático no se debe, sin embargo, ni a un déficit de recursos cognitivos (se tienen, pero no se usan, si no es robotizadamente), ni a la indiscriminación entre el bien y el mal, ni a la presencia de una patología clínica convencional como la psicosis, sino a una deformación del pensamiento, independiente totalmente de su cociente intelectual. En esto consiste la insensibilidad moral, la apatía emocional del fanático frío, capaz de realizar las mayores atrocidades sin perder la compostura (Alonso Fernández, 1995).

La creencia fanática no es una idea pensada verdaderamente, ha sido deglutida de forma compacta y monolítica, incrustada como un cuerpo sin fisuras que no se fragmenta ni tritura para su asimilación; es un pensamiento sin la robustez lógica que otorga la crítica, la duda o la exposición a pensamientos divergentes o críticos. De ese modo, el pensamiento enmudece en su praxis, no en su potencialidad. Queda derrotado. Finkielkraut (2000) recuerda en su obra $L a$ derrota del pensamiento que la habilidad de pensar se estrella contra dos escollos: la barbarie fanática o la estulticia zombi. Un ejemplo notable de ello lo constituyen los Jemeres Rojos de Camboya: llevaban control de las menstruaciones dentro de los matrimonios forzosos y aleatorios, apareando obligatoriamente a las mujeres durante sus períodos fértiles.

El fanático adopta una posición de obediente procesador de consignas, dejando así de ser un sujeto pensante y transformándose en un sujeto robotizado que llega a simular pensamiento, pero sólo reproduce miméticamente ideas estereotipadas y ejecuta acciones programadas en su hardware mental. Oz (2018, p. 38), experto en fanatismo, explica: "...todo lo que quiere el fanático, es darte un abrazo del que no escaparás, sacarte de inmediato del lugar paupérrimo donde estás hundido y llevarte al lugar fantástico y sublime que él ya ha descubierto y en cuyas 
alturas brilla desde entonces, unas alturas que de verdad, de verdad, de verdad, tú debes alcanzar de inmediato. Por tu bien y sólo por tu bien". Resulta convincente para desentrañar la complejidad fanática recurrir a Kernberg (2014), cuando ofrece una categorización de los narcisismos patológicos. En ella encontramos un grupo: el narcisismo instalado en una personalidad antisocial, que desemboca en "narcisismo maligno" arropándose de un argumentario que califica de pseudo-estúpido porque, por encima de todo, intenta proteger su self grandioso.

Baudrillard (2001) confirma este diagnóstico y culpa a la globalizada anomia y abulia moral de nuestro tiempo que todo lo inunda, de la muerte del espíritu, subrayando que uno de los agentes más catastróficamente destructores de la civilización occidental será la banalidad reinante en el pensamiento, en las informaciones, y en la irreflexión con que actuamos operatoriamente, sin tiempo ni ganas para hacernos eco del significado ni de las consecuencias. Esta misma banalidad occidental exacerba a aquellas otras ideologías salvíficas que tratan de erigirse en adalides de lo espiritual.

d) La normopatía esconde una potencialmente letal psicopatía: La apariencia engañosa de normalidad y hasta de trivialidad ofrecida a menudo por los más sangrientos genocidas de la historia fue resaltada por Arendt, famosa intelectual judía paradójicamente ligada a Heidegger (reconocido filósofo de quien se ha enfatizado su aquiescencia con el nazismo). Arendt (1963) asistió al juicio contra Eichmann en Jerusalén, siendo como fue uno de los principales responsables del genocidio judío, y después de verlo afirmó: "Me impresionó la manifiesta superficialidad del acusado, que hacía imposible vincular la incuestionable maldad de sus actos a ningún nivel más profundo de enraizamiento o motivación. Los actos fueron monstruosos, pero el responsable era totalmente corriente, del montón, ni demoníaco ni monstruoso".

De parecida forma, Bettelheim (1981) abunda en la idea del simplismo mental del fanático y su apariencia de funcionario del exterminio, que trata la vida humana con la misma distancia, flema y pulcritud con que llevaría a cabo cualquier asunto administrativo. Pone de manifiesto que uno cualquiera de los encargados de los campos de concentración podía ordenar el gaseamiento e incineración de centenares de personas por la mañana y acudir por la tarde con su porte más gallardo a una sesión en la ópera. Pues, a fin de cuentas, una característica esencial de las personalidades fanáticas es que utilizan su inteligencia para acallar sus emociones, por lo que no llegan a experimentar compasión o piedad, culpa o vergüenza por sus acciones. Las ejecutan con la insensibilidad e impasibilidad que un desparasitador fumiga los campos de maíz, o un registrador de la propiedad estampa el sello en los expedientes.

El mejor retrato moral de un fanático estándar lo ofrece uno de los grandes notarios de Auschwitz, Primo Levi (1981), cuando al ser preguntado por cómo eran o de qué pasta estaban 
hechos los esbirros nazis de las SS, escribe: "... estaban hechos de nuestra misma pasta, eran seres humanos medios, medianamente inteligentes, medianamente malvados: salvo excepciones, no eran monstruos, tenían nuestro mismo rostro, pero habían sido mal educados. Eran, en su mayoría, gente gregaria y funcionarios vulgares y diligentes: algunos fanáticamente persuadidos por la hoja de ruta nazi, muchos indiferentes, o temerosos del castigo, o deseosos de hacer carrera, o demasiado obedientes. Todos habían sufrido la aterradora deseducación suministrada e impuesta desde la escuela como habían querido Hitler y sus colaboradores..."

En otra obra de su imprescindible trilogía acerca de su estancia en el Lager más icónico, Si esto es un hombre, Primo Levi afirmaba con crudeza: "Los monstruos existen, pero son demasiado pocos para ser realmente peligrosos; más peligrosos son los hombres comunes, los funcionarios listos a creer y obedecer sin discutir..." (Levy, 1976). Cuenta cómo las mujeres judías embarazadas, condenadas irremisiblemente a la cámara de gas, eran atendidas con toda la corrección profesional por los médicos nazis durante el parto. Los sanitarios se aplicaban a fondo para que el nacimiento se desenvolviera adecuadamente: asepsia, lavado, corte limpio del cordón umbilical, etc, para a continuación exterminar a la madre y al bebé. Esta paradoja del comportamiento no se debe solamente a la saña crudelísima de los guardianes de los campos, sino a la disociación perfecta entre el acto médico del alumbramiento y el acto legal de la aplicación de una ley eugenésica que debía exterminar a los "bacilos humanos" de razas no arias. En tanto médicos, su conducta era primorosa, en tanto soldados ellos pensaban que también. Esa disociación les permitía dormir perfectamente tranquilos en sus casas por la noche después de acometer los más pavorosos horrores con suma pulcritud.

El pensamiento del fanático funciona de forma rígida, no está sujeto a permuta, a duda, a conmociones, ni siquiera a matizaciones. Sus ideas son escasas, formularias, nutridas de prejuicios, lemas, estereotipos o clichés. Poseen una visión hermética, compacta y encapsulada, fuera del curso del pensamiento. Por ello es fácilmente reproductor de los mensajes emitidos por líderes o figuras carismáticas e idealizadas. Por ello es frecuente la identificación imitativa de los comportamientos de los compañeros. Tanto es así que el no poner en duda las ideas preestablecidas y las consignas recibidas o repetir compulsivamente ciertos eslóganes es una demostración de lealtad y de ejemplaridad. Cuando un igual es dignificado y homenajeado como héroe o adepto modélico, sólo hay que emular su pensamiento y su comportamiento para merecer igual galardón. Daniel Lagache se refiere a un tipo de "idealizaciones heroicas" que operan como un resorte facilitador de imitaciones obedientes. De ese modo, no es preciso reconocer la propia insignificancia, pues se conserva el reflejo idealizado de la omnipotencia y de la invulnerabilidad encarnadas por el líder. 
Se puede no ser enteramente libre, pero legal y moralmente responsable de una acción cometida por cumplimiento fanático de una consigna. Se puede ser un militante ejemplar ante el microgrupo de los comulgantes de un régimen o sistema ideológico y, sin embargo, culpable y abyecto ante el resto de la humanidad. Tal es la rotunda contradicción que se colige de la satisfacción moral y la altiva arrogancia exhibida en los juicios por crímenes contra la humanidad practicados a tiranos, a genocidas o militantes ultra, que se enfrentan con perplejidad a las acusaciones que les lanzan, por estar imbuidos de su convicción de ser simples mediadores necesarios en un fin lógico y noble.

\section{Las epifanías fanáticas. Paroxismos de vida y muerte.}

Cuando el pensamiento fanatizado se transforma en acción genera, a su vez, actitudes paradójicas, muy representativas de proyectos y guiones de vida que son a un tiempo apogeo afirmativo y epígonos nihilistas. El destino de la acción fanática es un frenesí que se autofagocita en la exaltación narcisista de la idea única, proscribiendo y anulando todo lo herético o desviado, y proclamando la omnipotencia y el éxito de la verdad sacralizada. Por ello, en el escaparate de la acción-revelación fanática, el individuo totalitario muestra, entre otras, estas nuevas paradojas:

a) Gran coherencia y sistematización pese a no ser más que un autómata despersonalizado: Veamos: lo propio del cumplimiento fanático del deber es ejercer el trabajo metódica, y casi burocráticamente, con la pulcritud, la eficacia y la solvencia rutinaria de un trabajo mecánico cualquiera. No es exagerado referirse a estos individuos como máquinas de matar que asumen la "obediencia de un cadáver". El fanático es un autómata robotizado, al estilo de los reflejados por E.T.A. Hoffman (1993) en Los autómatas, un agente instrumental, no un actor responsable de su acción, pues se evalúa a sí mismo como pieza de un engranaje que lo ampara, responde de sus acciones por él y le reconoce como medio para un fin, mientras que lo desposee y lo aparta de su camino de individuación y subjetivación. Este es uno de los fines de los comunicados reivindicativos que efectúa una banda terrorista o un grupo fanático tras un atentado: presentarse como catalizador grupal de la responsabilidad, despojando de ella a los individuos concretos ejecutantes. Ellos son presentados como simple piezas logísticas perfectamente reemplazables. Son exclusivamente mensajeros o misioneros, actores que representan su papel en el guión, soldados que cumplen honorablemente su encargo, y si mueren en el empeño, mártires de la causa. La dialéctica culpable-inocente que acabo de exponer es planteada también por Marina (2000, p. 47) a propósito de los terroristas del Ulster: "¿Qué hacemos con los que apretaron el gatillo? ¿Puede ser un hombre al mismo tiempo héroe de una causa, tal vez justa, $y$ asesino? ¿Es que hay dos niveles de comportamiento, de justificación de las acciones, 
simultáneos, paralelos?, ¿habríamos de condecorar a una persona por justiciera y condenarla después por criminal? ¿Cómo podemos conciliar estas paradojas?"

El fanático cree actuar desde la coherencia con la orden, y esperan que su función les exonere de responsabilidad penal y moral, puesto que declinan su participación en tanto personas autónomas en los hechos. Recuerdo a propósito de esta dialéctica que Semprún $(2001$, p. 78$)$ se preguntaba respecto a esta paradoja por él mismo observada y padecida en el campo de concentración de Buchenwald: "¿Acaso no hay que ser un poco fanático para ser un buen soldado?". Cuando han de defenderse ante un tribunal, los torturadores esgrimen este argumento: son militantes de una causa o de un ejército militar o paramilitar, y en tanto tales están cumpliendo un acto bélico, declarado o no, de forma que su misión consiste en causar bajas en el enemigo para así debilitarlo. Declinan la culpa personal, pues son meros soldados leales a su bandera, a su causa y a su patria. No admiten responsabilidad de sus acciones, aún siendo autores materiales, pues sólo son el vehículo mediador de una misión, y como tal perfectamente impersonales y sustituibles. Golding (1954, p. 110) en su emblemática obra sobre la violencia humana, El señor de las moscas, se pronuncia sobre esta cuestión: "sin responsabilidades no hay sentido de culpa; sin culpa no hay madurez". En suma: se ha vaciado de su condición de sujeto pensante y moral para abrazar una identidad genérica, y ha desobjetalizado (Green, 2001) al objeto. Sin sujeto y sin objeto, la relación no existe y la anomia florece en medio de un escenario de muerte psíquica. (Boulanger, 2009).

La tortura sistemática o los atentados más sangrientos pueden realizarse impávidamente, desapasionadamente. Himmler adiestraba a sus esbirros de la S.S. para que fueran sobrehumanamente inhumanos, lo que equivale a ignorar lo humano (por lo tanto, abandonar los cánones humanos, para así librarse de cualquier elemento identificativo con la víctima), para luego aplastar y degradar lo humano. Veamos que, en este doble movimiento, el verdugo evita compartir con su víctima su rango humano, porque en cuanto torturador se pone por encima, $y$ porque ha denigrado y despersonalizado a la víctima, hasta convertirla en animal, en cosa o en materia amorfa. Sutil trama psicológica que elude el sentimiento de responsabilidad y de culpa. De hecho, Himmler expedientaba a los torturadores que realizaban su trabajo con odio personal, porque ello significaba que se mantenían en el rango de personas, y no meramente de soldados, considerando a las víctimas dignas de sentimientos, aunque fueran de odio, pues al hacerlo les reconocían estatus humano. Ello suponía apartarse de la función profesional y acercarse a la relación objetal.

Probablemente la paradoja se resuelva subiendo de nivel, aceptando que se pueden tener razones, pero no por ello patentar la verdad, que se puede defender una causa justa, pero sin embargo no tener derecho a violentar a otros para ello, que pueden encontrarse mitos 
trascendentales y justificativos (Marina y de la Válgoma, 2000) que avalen un comportamiento, pero ser completamente astigmáticos respecto a otras franjas de la realidad, a otras dimensiones del conocimiento. López de la Osa (1995) distingue a este respecto entre mito e ideología. El mito es inocuo, puede darse una construcción más o menos ficticia sobre algo, en lo que el individuo vive solo consciente a medias, pero no perturba a nadie. Ahora bien, cuando el mito se ideologiza, se convierte en arma intelectual para justificar la acción. La razón basada en la ideología excluye las razones discrepantes, se basa en una dialéctica de contrarios ("o tú o yo"), en cambio la razón basada en el mito admite las razones discrepantes, porque parte del diálogo. La ideología es conflictiva. Quizá el fanatismo de cualquier especie florezca cuando a una ideología (potencialmente conflictiva) se le superponga un ideal (sea disparatado, sea demente), una aspiración, una injusticia. Entonces su caudal destructivo puede ser inconmensurable. Dice Bordes Solanas (1999, p. 194): "Los ideales del fanático no sólo contienen la posibilidad de la universalización, sino que la exigen... Pero el fanático lleva en sí la semilla del desastre, la confianza en su infalibilidad (...)".

b) Se viven a sí mismos como víctimas, aunque actúan como impasibles verdugos: La dialéctica verdugo/víctima es esencial para comprender el totalitarismo. Su fermento es, en efecto, el sentimiento de agravio, ofensa y resentimiento, remontado a veces a un pasado histórico lejano o mitificado, pero que sigue alimentando distorsionadamente la transmisión oral de generación en generación. El victimismo legitimador es una de las caras de la violencia predatoria:

No hay fanático feroz que no argumente las razones legítimas que tiene para hacer lo que hace, la sagrada causa que justifica su violencia y el impecable sentido moral que le obliga a derramar la sangre del otro, que es el que tiene la culpa, por supuesto, él mismo nos obliga a liquidarlo (Lázaro, 2013, p. 202).

De hecho, enardecer el odio grupal contra un enemigo o idea adversaria o discrepante, sirve como aglutinante intragrupal, exacerbando de paso el sentimiento de pertenencia y participación dentro de un grupo, familia, clan, partido, nación... Un individuo manifiesta ser "uno de los nuestros" cuando comparte los odios, rencores y el afán de venganza con su grupo de pertenencia. En cambio, si se desvincula de los odios o rencillas del grupo, o se inhibe de sus planes para restaurar el honor agredido, pasa a ser percibido como un traidor, mereciendo la condena y en ocasiones la persecución o muerte a cargo de su propio clan, o cuando menos la marginación dentro de él. Es algo que observamos en los arrepentidos de las sectas, en los que escapan a las mafias organizadas, en los disidentes de partidos de pensamiento único, etc. El discrepante propio es un osado que daña más la coherencia y armonía dogmáticas que el crítico ajeno.

El victimismo se asienta en el resentimiento, emoción mezquina y turbia para Aristóteles, y se desarrolla gradualmente como reacción a lo que se prejuzga como actitud, intención o acción 
ofensiva por parte de otra persona. Lo esencial en el resentimiento, a diferencia de la reacción ante la ira, es la repetición del agravio o ataque que se cree haber padecido, favoreciéndose la impresión de que "llueve sobre mojado", de forma que no sólo se recibe pasiva o incontrolablemente la afrenta, sino que se sufre como revictimación. A menudo en el resentimiento se da la circunstancia de que el sujeto (grupo, pueblo o nación) interpreta algo como ofensivo, y su furia se encona mucho más por haber tenido la expectativa contraria: Tal ocurre cuando se espera apoyo y en lugar de recibirse, se obtiene una respuesta humillante o despectiva. Todo lo cual favorece que el sujeto, grupo, pueblo o nación receptores, máxime si son suspicaces o algo paranoides, valoren como una afrenta intolerable la respuesta obtenida. Una vez llegados aquí, lo siguiente es atribuir al otro una malévola intencionalidad y justificarse en el proyecto de recuperar el honor perdido, vengarse de la crítica recibida o reconquistar la ortodoxia cuestionada. La función básica del resentimiento es la de no olvidar la ofensa, alertando al sujeto para defenderse, contraatacar o-cual sucede en el fanático- para anticiparse al ataque temido con un ataque "preventivo".

El resentimiento es la piedra de toque de las formaciones paranoicas de tinte fanático, porque se nutre de daños, o amenazas comúnmente imaginarios, distorsionados o magnificados, incrementados desde dentro por el grupo de adeptos más fervorosos. El temor a la repetición de una crítica ya padecida en el pasado, o la ansiedad anticipatoria ante la crítica futura suministran argumentos aparentemente sólidos para una memoria histórica deformada o una cosmovisión incontrastable y mitificada. El recuerdo de lo doloroso queda fetichizado, momificado en el interior, inmune al paso del tiempo, incluso congelado, pudiendo aflorar anacrónicamente, cuando ya ha sido olvidado por todos. Podría pensarse, como lo hizo Vicario (1994), que el resentimiento proviene de un traumatismo psíquico no metabolizado, delirante incluso, que no puede ser incorporado narrativamente a la secuencia de la propia vida, por lo que persiste ajeno al desgaste. Lo primero que se busca a continuación es un responsable hacia quien dirigir el odio y la sed de venganza. La parte soterrada y oculta del resentimiento es la que se enrancia y fanatiza. Es un nódulo tóxico para el grupo.

Con frecuencia, dicho nódulo venenoso ideológicamente absolutista maquina con saña y pausadamente el resarcimiento posterior, cual ocurre con el terrorismo. El paso al acto sobrepasa en crueldad y destructividad la 'afrenta' recibida o imaginada, pero para equilibrar acción/reacción, agrandan el alcance del daño y la maldad de los victimarios. El fanático enfurecido justificará su acción criminal alegando que no hay seres inocentes (Ugarte, 1996), o que no cabe la neutralidad o la equidistancia: o se está dentro o se está fuera, o conmigo o contra mí, o eres un iniciado en la verdad o eres un pagano que puede perjudicarles. Cobran sentido especial las palabras de Oz: 
Lo cierto es que toda la fuerza del mundo no podría convertir a un enemigo en aliado. Con toda la fuerza del mundo no podría convertir a una persona fanática en una persona tolerante. Y con toda la fuerza del mundo no podría convertir a quien está sediento de venganza en un amigo. (Oz, 2015, p. 112).

Rosalind Minsky (1998) explica o, más bien, interpreta que la violencia ligada al extremismo arranca de un maniqueísmo infantil no superado, en virtud del cual, en cualquier confrontación, incluidos los debates, disputas y juegos, sólo se puede ser o ganador o perdedor, verdugo o víctima. Todo ello alimenta la polarización mental, le impide evolucionar hacia supuestos más complejos, mediatizados y realistas. Las simplificaciones son cómodas para los mentalmente perezosos, pero casi nunca son ciertas. Lo peor es que esa dialéctica está sustentada en las personalidades fanáticas por una interpretación de superioridad intelectual y moral. Jamás prospera la valoración de inferioridad del discurso, de vulnerabilidad de los silogismos, sino más bien el sentimiento de humillación o aplastamiento cuando el discurso o argumento rival persuade más. Pero, lejos de asumir la envidia al éxito ajeno y admitir la derrota, analizando las debilidades doctrinales y mostrando disposición a corregirlas o subsanarlas, se transformará en su contrario, ridiculizando al triunfador y dignificando la grandeza de la propia postura.

Una de las consecuencias probables es la reivindicación o la exigencia de retaliación por el agravio infligido. Ello se traduce en actitudes belicosas y enconadas en espera del resarcimiento o reconocimiento que antes se les negara. Si con esta actitud (paranoia sensitiva y autorreferencial) no se colman sus ambiciones, la siguiente fase puede ser violenta: se ataca al adversario vivenciado como verdugo y legitimándose la acción furibunda. A fin de cuentas, ¿qué es esto sino la plasmación del primitivismo moral en el que cíclicamente cae la humanidad, y todas sus epifanías: ideologías, doctrinas, vanguardias, tendencias, filosofías, modas, sistemas, generaciones? Afirmaba E. Wiesel (2001): "El fanático no aspira a convencer, sino a dominar, a subyugar, a aplastar. El fanático se erige a sí mismo en legislador, intérprete de la ley, fiscal, juez y verdugo".

No obstante, para un fanático, ocupar la posición de agraviado y víctima es muy complaciente, no renunciará fácilmente a ella, ni siquiera cuando se le concediera el desagravio o la reparación demandada (lo que ocurre por un exceso de paternalismo, condescendencia o propósito pactista por parte del crítico). Si aceptara la reparación se quedaría sin coartada para la aniquilación del adversario, aunque le brindaría el balón de oxígeno de la razón moral. Conviene que el discrepante no trate de ser conciliador, pues los correligionarios más fanatizados lo interpretarían como rendición, tampoco que muestre debilidad para desactivar su inquina, pues les estaría reforzando la imbatibilidad de su ortodoxia. (Hansberg, 1996).

c) El doctrinario convierte su sacrificio mortal, su inmolación, en la suprema afirmación de la vida: La pasión está muy ligada al fanatismo. La fuerza energética depositada en el objeto del fervor 
(idea, creencia, doctrina, partido, postura, club...) es magnetizadora. Tiene mucho de apetito vehemente, de padecimiento y tormento, de enajenación. Al ser un entusiasta posee más carisma, capacidad de fascinar; sale de sí, habita la idea en la que cree, emana seguridad, solvencia y liderazgo. Pero, por ello mismo, es menos dueño de sí cuanto más auténtico cree ser, porque está conformado por una identidad 'como si', una identidad apócrifa, un yo diluido en la idea o verdad misma que opera como satélite alienante que teledirige su conducta.

El fanático es un enfermo del Deseo, confundido con el supremo bien, la suprema verdad, la verdadera felicidad. Se mueve en el espejismo de realizar ese Deseo supremo de esparcir la Verdad Única, de fusionarse con lo Otro o Idea. Este desmesurado depósito de energía y fe contiene la terrible paradoja de la máxima vitalidad y el máximo nihilismo. La máxima afirmación de la vida, como búsqueda de un Absoluto perfecto, depara sufrimiento, a menudo muerte, o separación del grupo de pertenencia. El fervor proselitista segrega de los lazos de pertenencia previos, requiere una consagración, una entrega, una disponibilidad del mismo cariz que el voto religioso.

Vivir -sostiene Szpilka (2002)- se sustenta en el deseo de otra cosa, y eso suele ser algo que no tiene que ver con los preceptos de la biología (vivir no consiste sólo en sobrevivir y perpetuarse) o con los preceptos racionales. Anhelamos, y en esto se le suma Steiner (2000), un Absoluto, algo que dé un sentido humano o divino, no meramente animal, al hecho de estar aquí en el mundo. Pretendemos hallar significantes a los que supeditar y concatenar nuestra acción diaria. Es así que puede entenderse la aparente irracionalidad del sacrificio y la inmolación, revestidos incluso de una aureola de santidad, Lo sacrificial sublima el credo, la idea, la confirma en otro nivel trascendente, es una sanción que prestigia la doctrina. Si el fanático protagoniza una acción sacrificial salta al nivel de los elegidos: muriendo dota de sentido a la vida, la exalta, la ubica como un eslabón en la realización del Deseo. Reproduzco otras palabras de Szpilka, útiles para comprender la dinámica del dogmático mutado en mártir:

Que el sentido de la vida esté más allá de la vida misma, se especifica por el hecho de que la vida misma no tiene sentido si no hay algo por lo que vale la pena matar o morir. Hay que matar trascendiendo el matar para vivir y hay que morir trascendiendo la muerte natural animal. Así matar o morir devienen solamente significantes de la libertad subjetiva, libertad que por otro lado no es más que otra forma de testimoniar al ser (2004).

El Deseo, como vemos, puede más en el fanático que la supervivencia. Él es la más flagrante epifanía de esta paradoja de vida y muerte (Moreno y Fernández-Soriano, 1996). El sujeto queda fascinado por la apertura a una opción posible: el goce de la Tarea, la unción del sacrificio. La expresión tanática se apodera por completo del ser y utiliza los recursos de la vida (movimiento, inteligencia, palabra) para facilitar la aniquilación de la vida. 
d) El fanático se siente más plenamente sí-mismo cuanto más alienado está: ¿Cómo se llega a ello? De entrada, mediante una identificación fusiva y confusional de la idea y con el ideal. Seguramente que Chasseguet Smirguel lo consideraría otra enfermedad de la idealidad: En vez de figurar ésta como idea satélite del self, periférica y con la que se intercambian evolutivamente nuevas ideas a lo largo del desarrollo personal (tal como correspondería a la relación de cualquier sujeto con un pensamiento o creencia que va flexiblemente modificándose a lo largo de la vida a tenor de las experiencias cambiantes y de las distintas formas de ser que se van pautando en el crecimiento personal), en el fanático esa idea defendida acaba por introyección incorporativa formando parte del núcleo del self. De esta forma permanece inmune a cualquier desarrollo posterior, matización o pulimento. Es un quiste que se instala en el sí-mismo y se nutre de él, lo parasita, crece a sus expensas y no está sujeto a mutación o matización, tampoco a extirpación sin con ello atentar contra la propia supervivencia psíquica de la identidad. Como afirma Bordes Solanas (1999, p. 194): "Los ideales del fanático no sólo contienen la posibilidad de la universalización, sino que la exigen... Pero el fanático lleva en sí la semilla del desastre: la confianza en su infalibilidad (...). El fanatismo corrompe la más elevada moralidad".

Resulta muy pertinente invocar aquí la noción de certeza psicótica (Colina, 2017). La certeza de las creencias es estática, definitiva, impermeable a la refutación. En la certeza se está y se accede tras eliminar las dudas. Por eso distingue al alienado: su verdad es perfecta, redonda, impenetrable e incólume. Nada puede devaluarla ni degradarla ni mantener dialéctica con ella. Pero a mayor certeza, mayor alienación, puesto que se excluye más radicalmente el lugar del otro y de lo otro. Quien posee una certeza siente una autofascinación que le hace inmune a cualquier discusión o contrapunto. Si Le Bon (1895) viviera hoy, puede que expresara su pensamiento sobre la reproducción de las creencias fanáticas gracias a la afirmación, la repetición, la sugestión, el contagio y la mención de las figuras de autoridad, diciendo que se clonan sin sufrir mutaciones en el proceso. Me permito aconsejar desde aquí la lectura de Madre noche, de K. Vonnegut de 1961, donde se aprecian ésta y otras paradojas.

Sólo a costa de la alienación definitiva del self verdadero, a favor de un falso self o personalidad "como sí" que se apropia de la personalidad genuina. El sedimento fanático parasita el self verdadero y lo expulsa o lo niega. Para el observador extraño, el ortodoxo acérrimo es una persona alienada (en su sentido etimológico = un ser distinto del que se es), mientras para sí mismo se vive en la culminación plena de su proceso de realización personal. Vemos aquí el apogeo de la paradoja vitalismo-nihilismo, fruto de la confluencia entre las pulsiones de vida y las pulsiones de muerte. Idea ésta compartida por el premio Nobel de Literatura Naipaul, quien consideraba que se da en el fanatismo una letal confluencia de neuroticismo y nihilismo. 
Como hemos visto antes, que una vez que el proceso de identificación con la idea ha alcanzado el cénit, está más dispuesto que nunca a inmolarse o a sacrificarse a sí mismo en aras de la consecución de un objetivo o idea sobrevalorados. En efecto, como pone de relieve Bassols (1999) uno de los mecanismos que se muestran más activos en el adepto o prosélito es el de idealización o sobrevaloración de la idea al tiempo que la denigración, o ensombrecimiento al menos, de todo lo que escapa al foco selectivo de su interés. Esto produce un resultado sorprendente: cuanta mayor militancia alcanzan, de una parte provocan destrucción y muerte y de otra se sienten más orgullosos y satisfechos de sus hazañas, obliterando todo sentimiento de culpa. Su glorificación consiste en la omnipotencia de su destructividad. Así se entiende que mientras se causa dolor o injusticia a personas inocentes como consecuencia de la rigidez del pensamiento, el causante del problema goce de un estado beatífico, extasiado o eufórico por la vivencia de triunfo, de control y de desprecio sobre la víctima, máxime cuando se puede disponer de alguna retórica racional y justificativa que avale la sinrazón del desastre. Hemos de valernos de un mecanismo de escisión esquizo-paranoide, maniqueísmo o polarización en buenos y malos, elegidos-gregarios, portadores de la verdad-errados y ciegos a la misma.

Reparemos, como prueba de lo escrito, en que cuanto más cruenta, salvaje, inopinada y revulsiva sea una campaña totalitaria, tanto más convencidos de la nobleza de la causa, de la justificación de los medios y del altruismo de los fines estarán los ejecutantes, los soldados, los fieles, en esa inmensa franja gris de obedientes anodinos, de idiotas morales que componen la tropa adocenada de cualquier ideología totalitaria.

Nada mejor para concluir que el recordatorio de Primo Levi que pretende vacunarnos contra la pasividad o la indolencia del pensamiento que nos arrastra a aceptar las propuestas fanáticas:

Puesto que es difícil distinguir los profetas verdaderos de los falsos, es mejor sospechar de todo profeta; es mejor renunciar a la verdad revelada, por mucho que exalten su simplicidad y su esplendor, aunque las hallemos cómodas porque se adquieren gratis. Es mejor conformarse con otras verdades más modestas y menos entusiasmantes, las que se conquistan con mucho trabajo, poco a poco y sin atajos por el estudio, la discusión y el razonamiento, verdades que pueden ser demostradas y verificadas (Levi, 1989, p. 219).

\section{REFERENCIAS}

Alonso Fernández, F. (1995). El fanatismo y sus remedios. Psicopatología, 15(4): 191-197.

Arendt, H. (1963). Eichmann en Jerusalén. Un estudio sobre la banalidad del mal. Barcelona, España: Península.

Arendt, H. (1993). La condición humana. Barcelona, España: Paidós. 
Armengol Millans, R. (1999). El fanatismo, una perversión del narcisismo. Temas de Psicoanálisis, IV: 131-166.

Atwood, M. (2017). El cuento de la criada. Barcelona, España: Salamandra (Original 1985).

Baca, E. (2003). La construcción del enemigo. En E. Baca y M.L. Cabanas (Eds). Las víctimas de la violencia. Estudios psicopatológicos. Madrid, España: Triacastella.

Baca Baldomero, E. (2014). La agresividad y la violencia humanas. En F. Aznar FernándezMontesinos, E. Baca Baldomero y J. Lázaro (2014), La guerra contra la violencia (pp. 13-26). Madrid, España: Triacastella.

Bassols, R. (1999). Sobre fanatismo y violencia. Ensayo desde una perspectiva psicoanalítica. Temas de Psicoanálisis, IV: 167-179.

Baudrillard, J. (2001). Entrevista en El Cultural de El Mundo.

Bettelheim, B. (1981). Sobrevivir. El holocausto una generación después. Barcelona, España: Gedisa.

Bilbeny, N. (1993). El idiota moral. La banalidad del mal en el siglo XX. Barcelona, España: Anagrama.

Bion, W. (1975). Aprendiendo de la experiencia. Buenos Aires, Argentina: Paidós.

Bleichmar, H. (2005). Violencia, venganza y autojustificación. Aperturas Psicoanalíticas, 23. Recuperado de https://aperturas.org/articulo.php?articulo=0000405\&a=Violencia-venganzaautojustificacion

Bordes Solanas, M. (1999). Terrorismo y acción normativa. Isegoria. Revista de Filosofía Moral y Política, 20: 189-196.

Boulanger, G. (2009). Testigos de la realidad: trabajar psicodinámicamente con supervivientes del terror. Aperturas $31 . \quad$ Rsicoanalíticas, http://www.aperturas.org/articulo.php?articulo=0000579

Burris, C.T. y Rempel, J.K. (2008). Esperando con ansia los rumores de su muerte: antecedentes cognitivo-emocionales del odio. En M.A. Roldán Franco (Coord). Trastornos psicológicos en el siglo XXI (55-69). Madrid: Universidad Pontificia de Comillas.

Casado Esquius, L. (1989). Una visión del fanatismo desde la psicología humanista. Revista de Psiquiatría y Psicología humanista, 27-28, 148-153.

Chesterton, G. K. (2010). El fanático, en Los libros, la locura y otros ensayos. Madrid, España: El buey mudo.

Colina, F. (2017). Lo mínimo que hay que saber para hablar con los locos. Conferencia en "La otra psiquiatría". $\quad$ https://www.laotrapsiquiatria.com/2014/04/presentacion-conjunta-de-sobre-lalocura-y-estudios-sobre-la-psicosis/

Crastnopol, M. (2012). La indignación incontrolada: origen y consecuencias. Clínica e Investigación relacional, 6(1), 43-51.

De la Corte, L. (2006). La lógica del terrorismo. Madrid: Alianza Editorial.

Drakulic, S. (2008). No matarían ni una mosca. Criminales de guerra en el banquillo. Barcelona, España: Global Rhythm Press. 
Finkielkraut, A. (2000). La derrota del pensamiento. Barcelona, España: Anagrama.

García Gual, C. (2002). Los estragos del odio. Algunos ejemplos del mundo griego. En C. Castilla del Pino (Ed). El odio. (149-183) Barcelona: Tusquets.

Gómez de Liaño, I. (2019). Democracia, Islam, Nacionalismo. Madrid, España: Deliberar.

Golding, W. (1954). El señor de las moscas. Madrid, España: Unidad Editorial, 1999.

Green, A (2001): La muerte en la vida. Algunos puntos de referencia para la pulsión de muerte. Revista de psicoanálisis. 58 (2): 291-309.

Han, B.C. (2018). La expulsión de lo distinto. Barcelona, España: Herder.

Hansberg, O. (1996). La diversidad de las emociones. México: Fondo de Cultura Económica.

Hoffman, E.T.A. (1993). Los autómatas. San Sebastián, España: Muchnik.

Javaloy Mazón, F. (1983). Psicología del fanatismo (Tesis doctoral. Universidad de Barcelona). Recuperado de http://diposito.ub.edu/dspace/handle/2445/42753

Kernberg, O. (2007). El paciente narcisista casi intratable. Aperturas Psicoanalíticas, 46. Recuperado de http://www.aperturas.org/articulo.php?articulo=0000836

Kepel, G. (2001). La Yihad. Barcelona, España: Gedisa.

Lázaro, J. (2013). La violencia de los fanáticos. Un ensayo de novela. Madrid, España: Triacastela.

Le Bon, G. (1895). Psicología de las masas. Madrid, España: Morata (2005).

Lichtenberg, J. y Shapard, B. (2001). El odio rencoroso y vengativo y sus recompensas: una visión desde la teoría de los sistemas motivacionales. Aperturas Psicoanalíticas, 8. Recuperado de https://aperturas.org/articulo.php?articulo=0000157\&a=El-odio-rencoroso-y-vengativo-y-susrecompensas-una-vision-desde-la-teoria-de-los-sistemas-motivacionales

López de la Osa, J.R. (1995). La tolerancia: un signo de madurez cultural. Sociedad y Utopía, 5, 137150.

Marina, J.A. (2000). Crónicas de la ultramodernidad. Barcelona, España: Anagrama.

Marina, J.A. y De la Válgoma, M. (2000). La lucha por la dignidad. Barcelona, España: Anagrama.

Martín Solar, A.M. (2018). Origen del fanatismo. Una comprensión psicoanalítica a la luz del ideal y el duelo. Revista de Psicoterapia y psicosomática, 38(97): 31-48.

Moreno, E. y Fernández Soriano, J. (1996). La agresión: paradoja de vida y muerte. Revista de Psicoanálisis de la APM, 24, 9-28.

Muñoz Molina, A. (2001). Sefarad. Madrid, España: Alfaguara.

Ornstein, A. (2009). El destino de la rabia narcisista en psicoterapia. Aperturas Psicoanalíticas, 33. Recuperado de https://www.aperturas.org/articulos.php?id=0000608\&a=El-destino-de-la-rabianarcisista-en-psicoterapia

Vilas, M. (2018). Ordesa. Madrid, España: Alfaguara.

Oz, A. (2003). Contra el fanatismo. Madrid, España: Siruela. 
Oz, A. (2018). Queridos fanáticos. Madrid, España: Siruela.

Oz, A. (2015). Judas. Madrid, España: Siruela.

Puchol, M. (2016). El fanatismo en la vida cotidiana. Fanatismos. Madrid, España: APM y Lúa ediciones.

R.A.E. (1992). Diccionario de la Lengua Española. Madrid, España: Espasa Calpe.

Roca Barea, Ma E. (2018). 6 Relatos Ejemplares 6. Madrid, España: Siruela.

Sánchez-Sánchez, T. (2003). ¿Cómo se fabrica un fanático? Mecanismos psíquicos en la construcción de una mentalidad fanática. Papeles Salmantinos de Educación, 2: 111-133.

Semprún, J. (2001). Viviré con tu nombre. Morirás con el mío. Barcelona, España: Tusquets.

Seeling, B. y Rosof, L.S. (2002). Altruismo normal y patológico. Aperturas Psicoanalíticas, 10. Recuperado de https://aperturas.org/articulo.php?articulo=0000192\&a=Altruismo-normal-ypatologico

Steiner, G. (2001). Nostalgia del absoluto. Madrid, España: Siruela.

Szpilka, J. (2002). Creer en el inconsciente. Madrid, España: Síntesis.

Szpilka, J. (2004). Instinto, pulsión, deseo. Conferencia pronunciada en la Escuela de Enfermería de Salamanca, organizada por la APM.

Tobeña, A. (2017). Neurología de la maldad. Mentes predadoras y perversas. Barcelona, España: Plataforma.

Ugarte, J. (1996). El terrorista. Alienación del héroe romántico. Leviatán, 65: 13-22.

Utrilla Robles, M. (2018). Lideres y liderazgos. Madrid, España: El Duende.

VV.AA. (2002). El mundo después del 11 de septiembre de 2001. Barcelona, España: Península.

Vicario, J. M. (1994). Algunas consideraciones sobre traumatismo y resentimiento. Libro Anual de Psicoanálisis, (año 1994), 11-19.

Voltaire (1767). Tratado contra la intolerancia. Barcelona, España: Crítica (edición de 1999).

Vonnegut, K. (1987). Madre noche. Barcelona, España: Anagrama.

Vuillard, E. (2018). El orden del día. Barcelona, España: Tusquets.

Wiesel, E. (2001). Entrevista en ABC en julio de 2001.

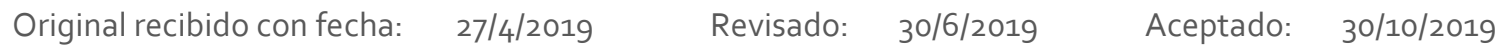

